\section{Yellow Cotyledon: A Seedling Disorder of Broccoli}

\section{Keith S. Mayberry', Kent J. Bradford ${ }^{2}$, and Vincent E. Rubatzky ${ }^{3}$ Department of Vegetable Crops, University of California, Davis, CA 95616}

Additional index words. Brassica oleraceae var. italica, seed vigor, accelerated aging, stand establishment

\begin{abstract}
A seedling disorder of broccoli (Brassica oleraceae L. var. italica) characterized by chlorotic cotyledons and delayed seedling growth is described. This disorder, termed "yellow cotyledon", has been observed in field plantings under high temperatures with some broccoli seed lots. Yellow-cotyledon disorder can be observed in laboratory germination tests if they are conducted under illumination, where unaffected seedlings will develop green cotyledons. Little relationship was found between overall seed vigor and the expression of yellow cotyledon by use of early germination counts and accelerated aging tests, although the most severely affected seed lots had been stored for several years. Field trials in 2 years showed that although seedlings with yellow-cotyledon disorder developed into normal plants, maturity was delayed and total yields were reduced.
\end{abstract}

Serious stand establishment problems occasionally occur in broccoli fields planted during the early fall in the Imperial Valley of California. Broccoli seed is typically precision planted at a desired spacing and irrigated by sprinklers until emergence. Seedlings generally emerge within 5 to 7 days, and the green cotyledons are readily visible. Stand establishment of broccoli was particularly poor in 1986, when several hundred hectares of plantings exhibited yellow (chlorotic) cotyledons after emergence. In most cases, the plants eventually outgrew the condition and showed apparently normal development to harvest. We conducted field and laboratory studies to investigate the nature of this seedling -disorder and to determine its consequences for crop establishment, growth, and yield.

A preliminary field trial was established on 24 Oct. 1986 at the Imperial Valley Agricultural Center, Holtville, Calif. A lot of 'Green Duke'-broccoli (lot 1 in Table 1) that had exhibited the yellow-cotyledon- disorder in commercial fields was sown with a precision belt planter at a $2.5-\mathrm{cm}$ spacing in double rows $25 \mathrm{~cm}$ apart on 107-cm-wide raised beds. Ten days after initial sprinkler irrigation, seedlings were thinned to leave only seedlings with either green or yellow cotyledons within a given $15-\mathrm{m}$ plot. Spacing between plants was adjusted to 10 to 15 $\mathrm{cm}$ between plants, and plots had statistically equivalent plant densities (averages of 70.6 and 68.9 plants per plot for yellow and green seedlings, respectively). The plots were in a

Received for publication 13 Nov. 1989. The cost of publishing this paper was defrayed in part by the payment of page charges. Under postal regulations,thispaper therefore must be hereby marked advertisement solely to indicate this fact.

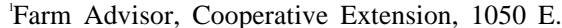
Hokon Road, Holtville, CA 92250

${ }^{2}$ Associate Professor. To whom reprint requests should be addressed.

${ }^{3}$ Specialist, Cooperative Extension completely randomized design with eight replications per treatment. The plots were given a standard broccoli culture program until harvest (Flint, 1985). A 6-m section from the center of each plot was harvested on 11 Feb. 1987. All marketable heads $\geq 7.5$ $\mathrm{cm}$ in diameter were trimmed to $20 \mathrm{~cm}$ in length, weighed, and counted.

A second field trial was established in the same location on 18 Sept. 1987. The same seed lot, planting, and cultural practices were used as in the previous year. After seedlings had emerged, 7.6-m plots were established by thinning some plots to contain only seedlings with yellow cotyledons, some with only green cotyledons, and some that contained a and after accelerated aging.' mixture of seedlings with green or yellow cotyledons in a proportion about equal to that which emerged. Spacing was adjusted to $\approx 15$ $\mathrm{cm}$ between plants in all plots. The second field trial was a randomized complete block design having eight replications. Four blocks were harvested as described above on 6 Jan. 1988, and the remaining four blocks on 13 Jan. 1988. Two harvest dates were selected to determine whether delaying harvest would compensate for the slower early growth of the yellow-cotyledon seedlings. A single onceover harvest was made at each date. The data were analyzed by analysis of variance (ANOVA) as a split plot with harvest dates as the main plots and cotyledon color as the subplots.

Germination tests were conducted on six lots of broccoli seed, some of which had exhibited the yellow cotyledon characteristic in field plantings. Four replicates of 50 seeds each were germinated on moist blotters in plastic sandwich boxes at cycling 20/30C with fluorescent light for $8 \mathrm{hr} \cdot \mathrm{day}^{-1}$ at the higher temperature. At 3 and 10 days, normal seedlings were counted according to Association of Official Seed Analysts (AOSA) rules (Yaklich, 1987). In addition to normal seedling evaluations, the seedlings were scored for the presence of green or yellow cotyledons. Accelerated aging tests were also conducted on each lot, as described in the AOSA Seed Vigor Testing Handbook (AOSA, 1983).

Seeds were suspended on a screen overwater in sealed jars at $45 \mathrm{C}$ for 1 or 2 days, then tested for germination as described above. Moisture content of the seeds at the end of the aging period was $\approx 23 \%$ (fresh-weight basis).

Cotyledons affected with what will be called the "yellow cotyledon disorder"
Table 1. Germination and occurrence of yellow-cotyledon disorder (YCD) of broccoli seed lots before

\begin{tabular}{|c|c|c|c|c|c|}
\hline \multirow[b]{2}{*}{ Cultivar } & \multirow[b]{2}{*}{ Lot } & \multirow{2}{*}{$\begin{array}{l}\text { Aging } \\
\text { period } \\
\text { (days) }\end{array}$} & \multicolumn{2}{|c|}{ Germination $(\%)$} & \multirow{2}{*}{$\begin{array}{l}\text { Seedlings with } \\
\text { yellow } \\
\text { cotyledon }(\%)^{y}\end{array}$} \\
\hline & & & 3 days & 10 days & \\
\hline \multirow[t]{12}{*}{ Green Duke } & 1 & 0 & $91 \mathrm{ab}$ & 93 a & $81 \mathrm{a}$ \\
\hline & & 1 & $74 \mathrm{~cd}$ & $80 \mathrm{bcd}$ & $75 \mathrm{a}$ \\
\hline & & 2 & $0 \mathrm{e}$ & $14 \mathrm{e}$ & $31 \mathrm{c}$ \\
\hline & 2 & 0 & $91 \mathrm{ab}$ & $95 \mathrm{a}$ & $82 \mathrm{a}$ \\
\hline & & 1 & $84 \mathrm{bc}$ & $90 \mathrm{ab}$ & $81 \mathrm{a}$ \\
\hline & & 2 & $0 \mathrm{e}$ & $20 \mathrm{e}$ & $8 \mathrm{de}$ \\
\hline & 3 & 0 & $82 \mathrm{C}$ & $88 \mathrm{abc}$ & $70 \mathrm{ab}$ \\
\hline & & 1 & $68 \mathrm{~d}$ & $76 \mathrm{~cd}$ & $68 \mathrm{ab}$ \\
\hline & & 2 & $0 \mathrm{e}$ & $20 \mathrm{e}$ & $25 \mathrm{cde}$ \\
\hline & 4 & 0 & $66 \mathrm{~d}$ & $90 \mathrm{ab}$ & $46 \mathrm{bc}$ \\
\hline & & 1 & $0 \mathrm{e}$ & $70 \mathrm{~d}$ & $2 \mathrm{e}$ \\
\hline & & 2 & $0 \mathrm{e}$ & $2 \mathrm{f}$ & $8 \mathrm{de}$ \\
\hline \multirow[t]{6}{*}{ Emperor } & 1 & 0 & $92 \mathrm{a}$ & $94 \mathrm{a}$ & $46^{\mathrm{x}}$ \\
\hline & & 1 & $92 \mathrm{a}$ & 94 a & 0 \\
\hline & & 2 & $0 \mathrm{e}$ & $22 \mathrm{e}$ & 2 \\
\hline & 2 & 0 & $79 \mathrm{~cd}$ & $82 \mathrm{ab}$ & 0 \\
\hline & & 1 & $77 \mathrm{~cd}$ & $78 \mathrm{~cd}$ & 0 \\
\hline & & 2 & $0 \mathrm{e}$ & $12 \mathrm{e}$ & 4 \\
\hline
\end{tabular}

${ }^{2}$ Mean separations within columns and cultivars by least significant difference ( $5 \%$ level) on angularly transformed data. Actual percentages are shown. The main effects of seed lot and aging treatment were highly significant $(1 \%$ level) for all parameters. The seed lot $\times$ aging interactions were significant for 3 -day germination and percent yellow cotyledon (1\% and 5\% levels, respectively).

'Seedlings exhibiting YCD as a percentage of the number of normal seedlings after 10 days.

'The 'Emperor' data were excluded from the statistical analysis due to the relative absence of YCD. 


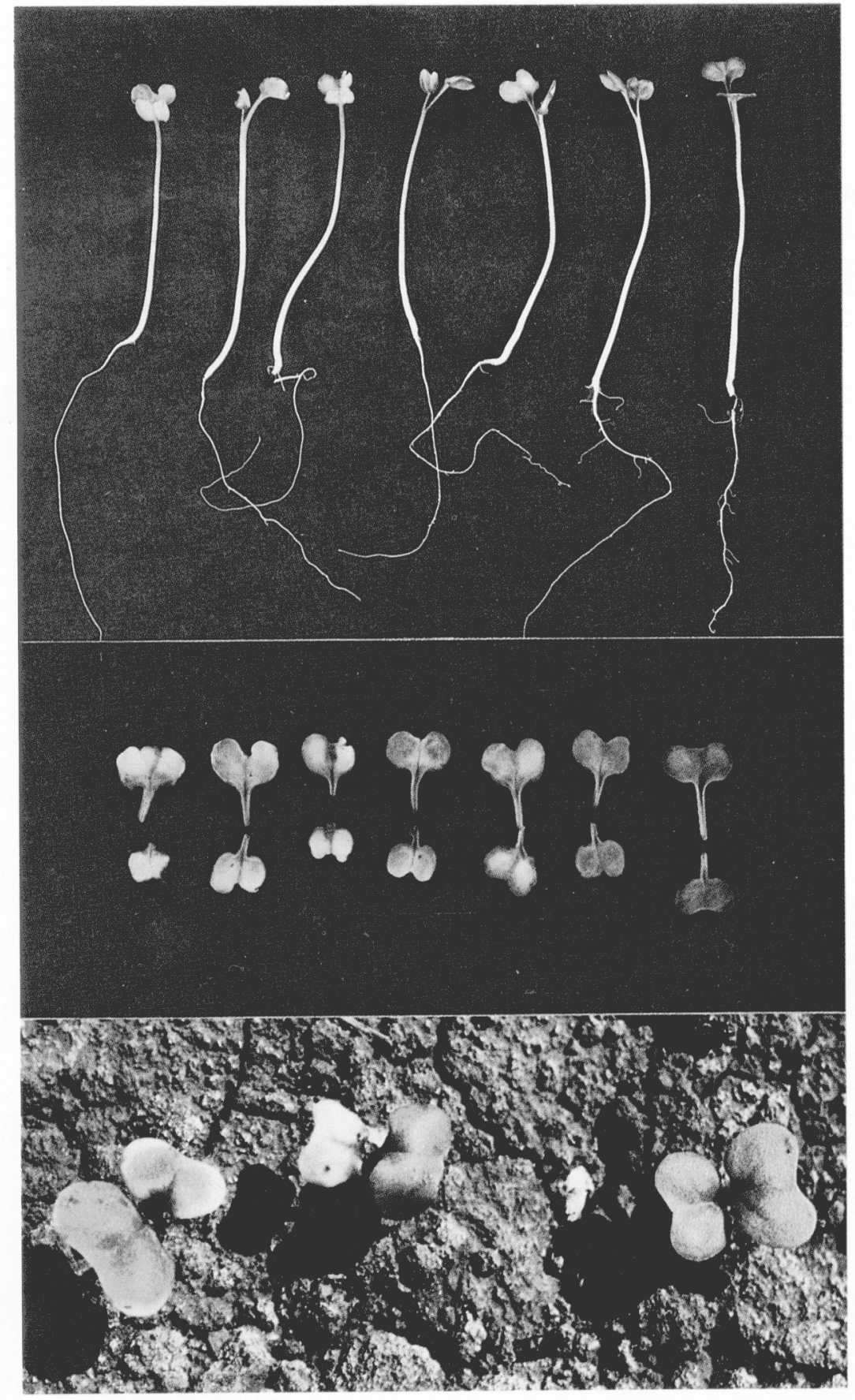

Fig. 1. (top) Representative seedlings from a standard germination test illustrating the range of yellowcotyledon disorder (YCD) symptoms from normal (right) to severely affected (left). (center) Cotyledons removed from the seedlings in the top panel. Note that the yellowing may be only on the cotyledon margins, only in the center of the cotyledons, in irregular patches, or over the entire cotyledon. Often, one cotyledon is more severely affected than the other. (bottom) Seedlings emerging in the field exhibiting some of the YCD symptoms observed (left to right): marginal chlorosis around both cotyledons, one cotyledon completely chlorotic, and a normal seedling.

(YCD) had a chlorotic appearance, generally yellow, but occasionally white or magenta (Fig. 1). Either one or both seedling cotyledons could be affected. Seedlings with white or magenta cotyledons usually died, while those with yellow cotyledons generally developed normal true leaves, but were retarded in growth. YCD in broccoli is similar in this respect to physiological necrosis or red-cotyledon disorder of lettuce, where the severity of the disorder is related to a reduction in seedling establishment and retarded growth (James, 1970; Tomas and Taylor, seedlings were also found in the cultivar Emperor, as well as in several breeding lines growing in trials. Trial plantings of seed lots in summer high-temperature conditions before the intended planting season have successfully identified low-vigor lots, including some exhibiting YCD.

Since YCD appeared to be associated with high-temperature stress in the field, accelerated aging tests were conducted in the laboratory to evaluate the occurrence of YCD under controlled conditions. Four lots of 'Green Duke' and two lots of 'Emperor' that had exhibited some YCD in field plantings were tested. Germination percentages in standard tests were $\geq 82 \%$ for all lots after 10 days (Table 1). Except for the yellow cotyledons, most affected seedlings were normal according to seed testing rules (Fig. 1). All lots except 'Green Duke' lot 4 germinated at $\geq 79 \%$ after 3 days, indicating good seed vigor. The accelerated aging tests tended to confirm this conclusion, as the reductions in germination after 1 day of aging were relatively slight for most lots (Table 1). However, 2 days of aging severely reduced germination in all lots. Survival of seed after exposure to accelerated aging conditions has been correlated with longevity in storage and has been suggested as a vigor test for Brassica seeds (Matthews, 1980; Powell and Matthews, 1984). However, accelerated aging did not induce YCD in seed lots where -its occurrence was low (Table 1). In the 'Emperor' lots where YCD was not present in unaged seeds, only a low percentage of seedlings with yellow cotyledons was detected even after 2 days of accelerated aging. All four lots of 'Green Duke', however, exhibited high percentages of YCD. After 2 days of accelerated aging, when total germination was severely reduced, the percentage of seedlings with YCD was very low, suggesting that seeds with this disorder might be more susceptible to loss of viability under these adverse conditions.

Information relevant to the production and handling of seed lots tested here was not available. Therefore, it cannot be determined if observed seedling and yield performance among seed lots was attributable to seed production conditions or subsequent handling. The percentage of seedlings with yellowcotyledon disorder following accelerated aging is underestimated in 'Green Duke' lot 4 because no seeds had germinated by day 3 , and many of the seedlings with initially yellow cotyledons had greened by the 10-day count. The time for scoring for YCD may need to be adjusted according to the germination rate of seed lots to allow sufficient time for cotyledon greening to occur in unaffected seedlings. It should be noted that if the germination tests had been done in the dark, all four lots of 'Green Duke' would have had acceptable final germination percentages, and only lot 4 would have been suspected of having low vigor due to the lower 3-day percentages, since the YCD disorder only became apparent after chlorophyll developed in the normal seedlings (Fig. 1). Although AOSA rules "for testing do not 
Table 2. Effect of yellow-cotyledon disorder on yield of broccoli. ${ }^{*}$

\begin{tabular}{cccccc}
\hline \hline Year & Harvest & $\begin{array}{c}\text { Seedling } \\
\text { type }\end{array}$ & $\begin{array}{c}\text { Total } \\
\text { wty } \\
(\mathrm{kg} / \mathrm{plot})\end{array}$ & $\begin{array}{c}\text { No. heads } \\
\text { harvested/plot }\end{array}$ & $\begin{array}{c}\text { Plants } \\
\text { harvested } \\
(\%)\end{array}$ \\
\hline 1986 & 1 & Green & $10.0 \mathrm{a}$ & $48.7 \mathrm{a}$ & $71 \mathrm{a}$ \\
& & Yellow & $7.4 \mathrm{~b}$ & $37.2 \mathrm{~b}$ & $54 \mathrm{~b}$ \\
1987 & 1 & Green & $3.01 \mathrm{c}$ & $15.2 \mathrm{c}$ & $31 \mathrm{c}$ \\
& & Mixed & $3.12 \mathrm{c}$ & $13.5 \mathrm{c}$ & $27 \mathrm{~cd}$ \\
& \multirow{2}{*}{2} & Yellow & $2.19 \mathrm{~d}$ & $10.0 \mathrm{~d}$ & $21 \mathrm{~d}$ \\
& & Green & $5.57 \mathrm{a}$ & $27.2 \mathrm{a}$ & $55 \mathrm{a}$ \\
& & Mixed & $5.26 \mathrm{ab}$ & $24.8 \mathrm{ab}$ & $49 \mathrm{ab}$ \\
& & Yellow & $4.94 \mathrm{~b}$ & $23.0 \mathrm{~b}$ & $43 \mathrm{~b}$ \\
\hline
\end{tabular}

${ }^{2}$ Mean separations within columns for each trial by least significant difference (5\% level).

'Total weight of heads $>7.5 \mathrm{~cm}$ diameter harvested per plot.

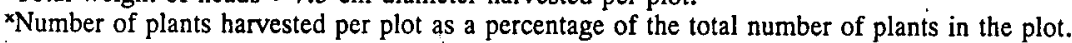

specify light, it is a common practice to germinate the Brassica seeds in light to make evaluations easier (E. Chirco, personal communication).

In the 1986 field trial, the yield from plots containing only green-cotyledon seedlings significantly exceeded yield from plots containing only yellow-cotyledon seedlings for weight, number of heads, and percentage of plants harvested (Table 2). It is possible that had harvest been delayed, the yield from the YCD plots might have achieved that of the control plots. This was tested in the second field trial by harvesting on two dates. Again, the yield from plots containing only seedlings exhibiting YCD was significantly less than that from plots with only green seedlings (Table 2). A mixed population of seedlings with yellow or green cotyledons resulted in an intermediate yield. Delaying harvest increased the total yields, but did not alter the relationships among the groups (seedling type $\times$ harvest date interaction was not significant). At both harvest dates, the percentage of plants with marketable heads decreased as the population of seedlings with YCD increased (Table 2), but weight per head was unaffected (data not shown). Thus, the yield reduction due to $Y C D$ resulted from a delay in maturity and fewer plants producing marketable heads.

We have documented the occurrence of a new seedling disorder of broccoli, termed yellow-cotyledon disorder. Like physiological necrosis or red-cotyledon disorder of lettuce (Bass, 1970; Dempsey and Harrington, 1951; James, 1970), YCD appears to be associated with advanced seed age (the 'Green Duke' seed lots used here had been in storage for $\approx 5$ years) and stressful environmental conditions, but there was not a close relationship between overall seed vigor level and the occurrence of YCD. Seed, especially aged broccoli seed, should be tested by seed suppliers and growers for stress susceptibility in preliminary field plantings. Unlike physiological necrosis of lettuce (Tomas and Taylor, 1989), YCD was not induced or increased by accelerated aging conditions (Table 1). We have documented that delayed and reduced yields can result from the occurrence of YCD in the field. We recommend that broccoli seed germination tests be conducted in the light to detect YCD, since it was not consistently related to either total germination or the rate of germination and would not be apparent in etiolated seedlings.

\section{Literature Cited}

Association of Official Seed Analysts. 1983. Seed vigor testing handbook. Assn. Off. Seed Anal., Springfield, Ill.

Bass, L.N. 1970. Prevention of physiological necrosis (red cotyledon) in lettuce seeds (Lactuca sativa L.). J. Amer. Soc. Hort. Sci. 95:550553.
Dempsey, W.H. and J.F. Harrington. 1951. Red cotyledon of lettuce. Calif. Agr. 5:4.

Flint, M.L. (ed.). 1985. Integrated pest management for cole crops and lettuce. University of California, Div. Agr. and Natural Resources Publ. 3307.

James, E. 1970. The nature and performance of red cotyledon lettuce seedlings, (Lactuca sativa L.). J. Amer. Soc. Hort. Sci. 95:316-319.

Matthews, S: 1980 . Controlled deterioration: A new vigour test for crop seeds, p. 647-660. In: P. Hebblethwaite (ed.). Seed production. Butterworths, London.

Powell, A.A. and S. Matthews. 1984. Application of the controlled deterioration vigour test to detect seed lots of Brussels sprouts with low potential for storage under commercial conditions. Seed Sci. \& Technol. 12:649-657.

Tomas, T.N. and A.G. Taylor. 1988. Studies on physiological necrosis in lettuce seeds. HortScience 23(3):813. (Abstr.)

Tomas, T.N. and A.G. Taylor. 1989. A stress test to induce physiological necrosis in lettuce seeds, p. 212-220. In: M.D. Orzolek, D.R. Daum, and W.G. Pill (eds.). Proc. Intl. Conf. on Stand Establishment for Hort. Crops. The Pennsylvania State Univ., University Park, Pa.

Yaklich, R.W. (ed.). 1987. Association of official seed analysts. Rules for testing seeds. J. Seed Technol. 6:1-125. 